\title{
Strong inflammatory response and Th1-polarization profile in children with acute lymphoblastic leukemia without apparent infection
}

\author{
E. PÉREZ-FIGUEROA ${ }^{1}$, M. SÁNCHEZ-CUAXOSPA ${ }^{1}$, K.A. MARTÍNEZ-SOTO ${ }^{1}$, N. SÁNCHEZ-ZAUCO ${ }^{1}$, \\ A. MEDINA-SANSÓN ${ }^{2}$, E. JIMÉNEZ-HERNÁNDEZ ${ }^{3,4}$, J.R. TORRES-NAVA ${ }^{3}$, J.M. FÉLIX-CASTRO ${ }^{4}$, \\ A. GÓMEZ ${ }^{5}$, E. ORTEGA ${ }^{6}$ and C. MALDONADO-BERNAL ${ }^{1}$
}

\author{
${ }^{1}$ Immunology and Proteomics Research Laboratory, Children's Hospital of Mexico Federico Gómez, Mexico, D.F.; \\ ${ }^{2}$ Department of Hematology-Oncology, Children's Hospital of Mexico Federico Gómez, Mexico, D.F.; ${ }^{3}$ Oncology Service, \\ Children's Hospital Moctezuma, Mexico, D.F.; ${ }^{4}$ Oncology Service, Highly Specialized Unit, General Hospital National \\ Medical Center La Raza, Mexican Institute of Social Security, Mexico, D.F.; ${ }^{5}$ Research Unit on Infectious Diseases, \\ Pediatric Hospital, National Medical Center XXI Century, Mexican Institute of Social Security, Mexico, D.F.; \\ ${ }^{6}$ Department of Immunology, Institute for Biomedical Research, \\ National Autonomous University of Mexico, Mexico, D.F., Mexico
}

Received November 6, 2015; Accepted December 17, 2015

DOI: $10.3892 /$ or.2016.4657

\begin{abstract}
Children with acute lymphoblastic leukemia (ALL) often present fever. Febrile states are usually associated with infectious processes that generate an inflammatory response involving various molecules, including cytokines. However, an inflammatory response may also occur in the absence of infection. We hypothesized that the levels of inflammatory cytokines are increased in children with ALL without apparent infection. The serum levels of 13 cytokines in 99 patients with ALL and 48 non-oncological patients without apparent infection were measured using multiplex analyte profiling technology $\left(\right.$ Lumine $\left.{ }^{\circledR}\right)$. The concentration of circulating pro-inflammatory cytokines associated with fever was similar between patients with ALL and fever at diagnosis and those without fever. The levels of tumor necrosis factor $\alpha$, interleukin (IL)-6, IL-8, monocyte chemoattractant protein-1 (MCP-1) and
\end{abstract}

Correspondence to: Dr Carmen Maldonado-Bernal, Immunology and Proteomics Research Laboratory, Children's Hospital of Mexico Federico Gómez, Dr. Márquez 162, Colonia Doctores, C.P. 06720, Mexico, D.F., Mexico

E-mail: cmaldobe@yahoo.com

Abbreviations: ALL, acute lymphoblastic leukemia; TNF- $\alpha$, tumor necrosis factor $\alpha$; IFN- $\gamma$, interferon- $\gamma$; IL-1, interleukin-1; TGF- $\beta$, transforming growth factor $\beta$; MCP-1, monocyte chemoattractant protein-1; Th, T helper

Key words: acute lymphoblastic leukemia, pro-inflammatory cytokines, Th1 immune response, sterile inflammation, circulating cytokines, immunoregulation
IL-10 were higher in patients with ALL vs. the control group $(\mathrm{P}<0.05)$. Moreover, the levels of the $\mathrm{T}$ helper 1 (interferon- $\gamma$ and IL-12) cytokines were higher in patients with ALL vs. the control group. Transforming growth factor $\beta$ was lower in patients with ALL vs. the control group $(\mathrm{P}<0.05)$. The levels of IL-1 $\beta$, IL-2, IL-4, IL-13, and IL-17 were similar in the two groups. Our results indicate that the circulating levels of seven of the important studied cytokines are elevated in patients with newly diagnosed ALL without apparent infection, reflecting a strong and deregulated inflammatory state in this disease, with a Th1-polarization profile.

\section{Introduction}

Acute lymphoblastic leukemia (ALL) is the most common pediatric malignancy in childhood (0-14 years), constituting slightly less than one-third of all childhood cancers diagnosed, whereas it constitutes approximately $10 \%$ of the cancers diagnosed among adolescents and young adults (15-19 years) (1).

Cytokines, which were originally identified as products of immune cells, are small secreted proteins that have specific effects on the interactions and communication between cells. Cytokines are important mediators of immune responses that are secreted in response to different infectious and noninfectious stimuli. Different cytokines are able to stimulate or inhibit cell growth, regulate cell differentiation, induce cell chemotaxis, and modulate the expression of other cytokines. The balance among different cytokines is very important for the maintenance of the processes regulated by them, as they have been shown to participate in both the initiation and progression of several pathological processes, such as chronic inflammation and cancer (2).

Inflammation as a result of trauma, ischemia-reperfusion injury, or chemically induced injury typically occurs in the 
absence of microorganisms and has, therefore, been termed 'sterile inflammation'. Sterile inflammation occurs in acute conditions and is similar to microbial-induced inflammation in that it is marked by the recruitment of neutrophils and macrophages and the production of pro-inflammatory cytokines and chemokines, such as tumor necrosis factor- $\alpha$ (TNF- $\alpha$ ) and interleukin-1 (IL-1) (3). The triggers of sterile inflammation are still under investigation, and the pathways that transduce sterile inflammatory signals have not been completely clarified. Currently, most of the innate immune pathways that are activated during infection have been implicated in sterile inflammation, although distinct signaling pathways of sterile inflammation exist $(3,4)$. Whether immune pathology ensues after acute sterile inflammation, depends on the balance between pro-inflammatory and resolution pathways.

It is now evident that pattern recognition receptors (PRRs) also recognize non-infectious material that can cause tissue damage, as well as endogenous molecules that are released after tissue injury or cell death. These endogenous molecules have been termed damage-associated molecular patterns (DAMPs). DAMPs have similar effects to pathogen-associated molecular patterns (PAMPs) in terms of their ability to activate inflammatory pathways (5).

In clinical practice, most patients with newly diagnosed ALL present febrile episodes, which are usually assumed to be associated with an infectious process. However, in $80 \%$ of cases, no infection can be demonstrated $(6,7)$. The levels of circulating cytokines have been studied in patients with ALL presenting fever and neutropenia in the presence of overt infection $(8,9)$; however, to date, no studies of patients with ALL and fever without apparent infection have been published. It is important to characterize the inflammatory profile in patients with ALL presenting febrile episodes without clinically apparent infection, as this may influence the medical management of these patients. The aim of this study was to assess whether the levels of inflammatory cytokines are increased in patients with ALL without apparent infection.

\section{Materials and methods}

Study population. The study was conducted at the Hospital Infantil de México Federico Gómez and at the Hospital Pediátrico Moctezuma in Mexico City, and was approved by the ethics committees of both institutions. Signed informed consent was obtained from all parents, and assent was obtained from all children older than 9 years of age. The study included 99 children with ALL (newly diagnosed) from the Department of Oncology of the two hospitals, and 48 non-oncological patients (controls) who visited the Department of Orthopedics and Ophthalmology of the Hospital Infantil de México Federico Gómez for consultation and/or preoperative analysis. We confirmed that patients with ALL included in this study had no apparent clinical infection at diagnosis, the point at which the blood sample used in this study was taken. We conducted a detailed review of the clinical records to confirm that the specimens of patients with ALL were negative for all microbiological tests of blood, urine, and spinal fluid (LCR) by culture and/or PCR. The exclusion criteria were: presence of any evident infection at diagnosis, anti-inflammatory or antimicrobial treatment, cancer-specific therapies, primary or secondary immunodeficiencies, or recent blood-component transfusion.

Sample collection. Peripheral blood was collected in a Vacutainer tube (BD Vacutainer ${ }^{\circledR}$ ) without anticoagulant. After clotting, the tubes were centrifuged at $1,000 \mathrm{xg}$ for $10 \mathrm{~min}$ at $4^{\circ} \mathrm{C}$. Serum samples were stored at $-80^{\circ} \mathrm{C}$ until analysis.

Determination of important cytokine and chemokine levels in the serum. Cytokines and chemokines (IL-1 $\beta$, TNF- $\alpha$, IL-6, MCP-1, IL-8, IL-10, IFN- $\gamma$, IL-12p70, IL-2, IL-4, IL-13 and IL-17) were quantified in the sera of patients and controls using the multiplex analyte profiling (xMAP) technology with the Millipore HSCYTOMAG-60K kit (Luminex ${ }^{\circledR}$, magnetic beads; Millipore, Billerica, MA, USA), and were read on a MAGPIX apparatus (Milliplex ${ }^{\circledR}$; Millipore). All reagents were provided in the kit and prepared according to the manufacturer's protocol. Each sample was analyzed in duplicate, and the mean concentration of each analyte was calculated using a parameter logistic fitted curve generated from the standards.

TGF- $\beta$ was determined in serum samples from 88 patients with ALL and 48 controls using an ELISA set (BD OptEIA ${ }^{\mathrm{TM}}$; BD Biosciences) according to the manufacturer's protocol.

Statistical analyses. Values are plotted as the median with range. Comparisons between groups were performed by comparing medians using the Mann-Whitney U test. All statistical analyses were performed using the SPSS program V22, and $\mathrm{P}<0.05$ was considered to indicate a statistically significant result.

\section{Results}

Clinical characteristics. The characteristics of the patients with ALL and the non-oncological patients included in the study are described in Table I. The ALL group included both de novo precursor B-lineage and T-lineage leukemia cases. Among the patients with ALL, 34\% (34 patients) had fever at admission, $50 \%$ of whom (17 out of 34 patients) had neutropenia. The characteristics of the patients with ALL and fever and patients with ALL without fever are described in Table II.

After admission to the hospital, patients with ALL with fever included in the study were treated with antimicrobial and antipyretic drugs. No patient presented a positive microbial culture during the following week and patients with ALL survived for at least one week after admission.

The concentration of circulating pro-inflammatory cytokines associated with fever is similar between patients with ALL and fever at diagnosis and those without fever. We analyzed the levels of circulating pro-inflammatory cytokines (IL-1 $\beta$, IL- 6 , and TNF- $\alpha$ ). The concentrations of IL-1 $\beta$, IL- 6 , and TNF- $\alpha$ were not statistically different between the two groups of patients (with and without fever) $(\mathrm{P}>0.05)$.

We found no significant differences in the levels of cytokines associated with fever (IL-1 $\beta$, TNF- $\alpha$, and IL-6) in the sera of patients with ALL with and without fever at admission (Fig. 1). 
Table I. Demographic characteristics of the study population.

\begin{tabular}{lcc}
\hline & $\begin{array}{c}\text { ALL } \\
\text { patients }\end{array}$ & $\begin{array}{c}\text { Non-oncological } \\
\text { patients }\end{array}$ \\
\hline No. of subjects & 99 & 48 \\
Gender (F/M) & $40 / 59$ & $23 / 25$ \\
Age, mean (range) & $7.5(0.25-17)$ & $9.1(5-17)$ \\
in years & & Ophthalmologic, \\
Diagnosis & ALL & \\
Immunological & & \\
classification & & \\
Lineage B & & \\
Lineage T & 64 & \\
Biphenotypic & 14 & \\
Not classifiable & 3 & \\
With fever & 18 & \\
\hline
\end{tabular}

ALL, acute lymphoblastic leukemia.

Table II. Characteristics of the patients with ALL with fever or without fever.

\begin{tabular}{lcccc}
\hline Patients & $\begin{array}{c}\text { Age } \\
(\text { years })\end{array}$ & $\begin{array}{c}\text { Gender } \\
(\mathrm{F} / \mathrm{M})\end{array}$ & $\begin{array}{c}\text { Leukocytosis } \\
\left(10^{3} / \mu \mathrm{l}\right)\end{array}$ & $\begin{array}{c}\text { Neutrophils } \\
\text { (total) }\end{array}$ \\
\hline $\begin{array}{l}\text { Fever } \\
(\mathrm{n}=34)\end{array}$ & $6.5 \pm 0.69$ & $(14 / 20)$ & $147.9 \pm 59.5$ & $3,593 \pm 202.0$ \\
$\begin{array}{l}\text { No fever } \\
(\mathrm{n}=62)\end{array}$ & $8.2 \pm 0.62$ & $(25 / 37)$ & $62.3 \pm 13.8$ & $1,801 \pm 577.5$ \\
P-value & & 0.085 & 0.076 & 0.289 \\
\hline
\end{tabular}

ALL, acute lymphoblastic leukemia.

Patients with ALL show a pro-inflammatory state at diagnosis. We analyzed the levels of circulating pro-inflammatory cytokines (IL-1 $\beta$, IL-6, and TNF- $\alpha$ ) associated with the production of fever; the concentrations of IL- 6 and TNF- $\alpha$ were higher in the group of patients with ALL than they were in the control group $(\mathrm{P}<0.05)$. Although the concentration of IL-1 $\beta$ was not statistically different between the two groups, it was observed that the median concentration was higher in the ALL group than that in the control group (3.2 vs. $3.2 \mathrm{pg} / \mathrm{ml}$ ) (Fig. 2A). The median TNF- $\alpha$ concentration in the control group was $13.60 \mathrm{pg} /$ $\mathrm{ml}$ (range, $40-211.6 \mathrm{pg} / \mathrm{ml}$ ), whereas the median concentration in the ALL group was $65.40 \mathrm{pg} / \mathrm{ml}$ (range, 1.24-496 pg/ml) (Fig. 2B). The IL-6 concentration was $3.20 \mathrm{pg} / \mathrm{ml}$ (range, $0.00-87.85 \mathrm{pg} / \mathrm{ml}$ ) in the control group and $8.79 \mathrm{pg} / \mathrm{ml}$ (range, 0.00-615 pg/ml) in the ALL group (Fig. 2C). These results suggest the presence of an important pro-inflammatory profile in patients with ALL at diagnosis in the absence of clinically apparent infection.
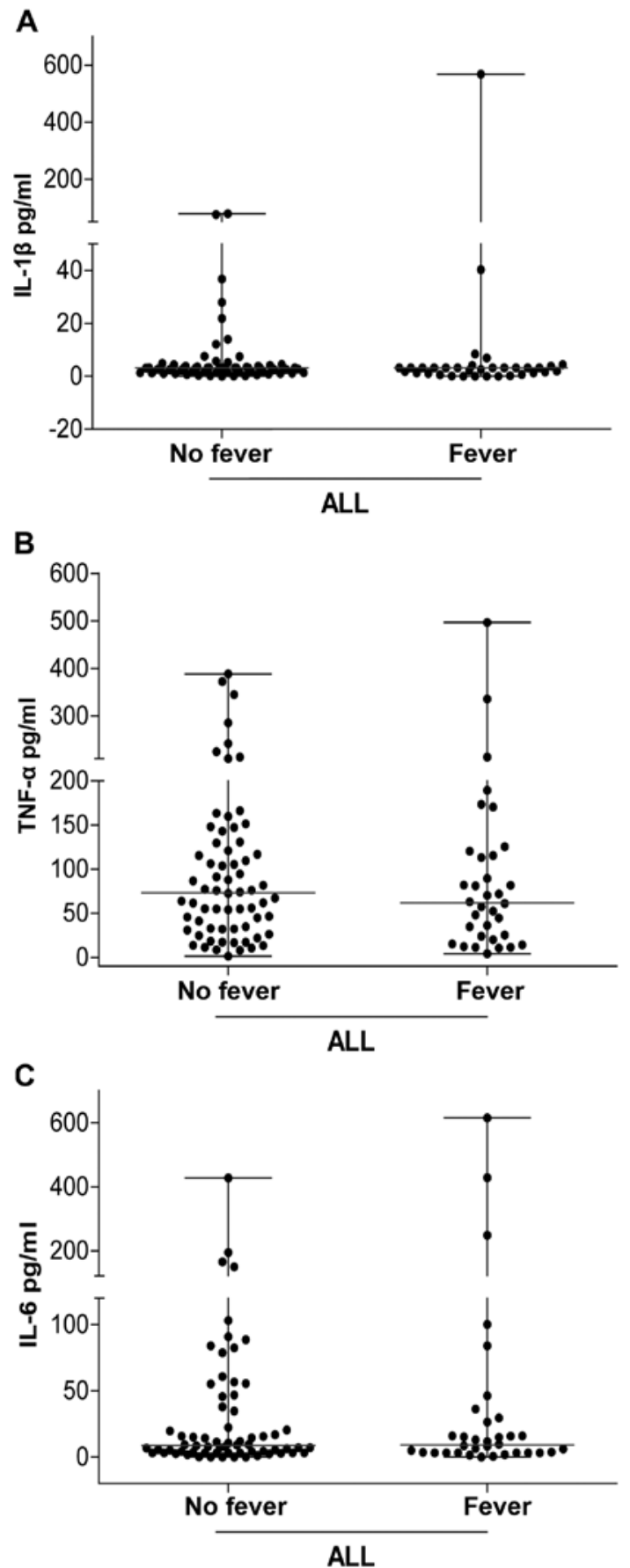

Figure 1. The levels of circulating pro-inflammatory cytokines in patients with acute lymphoblastic leukemia (ALL) were similar in the presence and absence of fever. The serum levels of (A) interleukin (IL)-1 $\beta$, (B) tumor necrosis factor (TNF)- $\alpha$, and (C) IL-6 in patients with ALL and fever and without fever were measured by xMAP. The values are plotted as the median with range. Comparisons between groups were performed using the MannWhitney $\mathrm{U}$ test. $\mathrm{P}<0.05$ is considered to indicate a statistically significant result.

The concentration of circulating pro-inflammatory chemokines is elevated in patients with ALL at diagnosis. The pro-inflammatory cytokines IL- $1 \beta$ and TNF- $\alpha$ induce the production of two important inflammatory chemokines that participate in carcinogenesis, MCP-1 and IL-8. As we found elevated levels of TNF- $\alpha$ in children with ALL, we were interested in determining the levels of these chemokines in these 

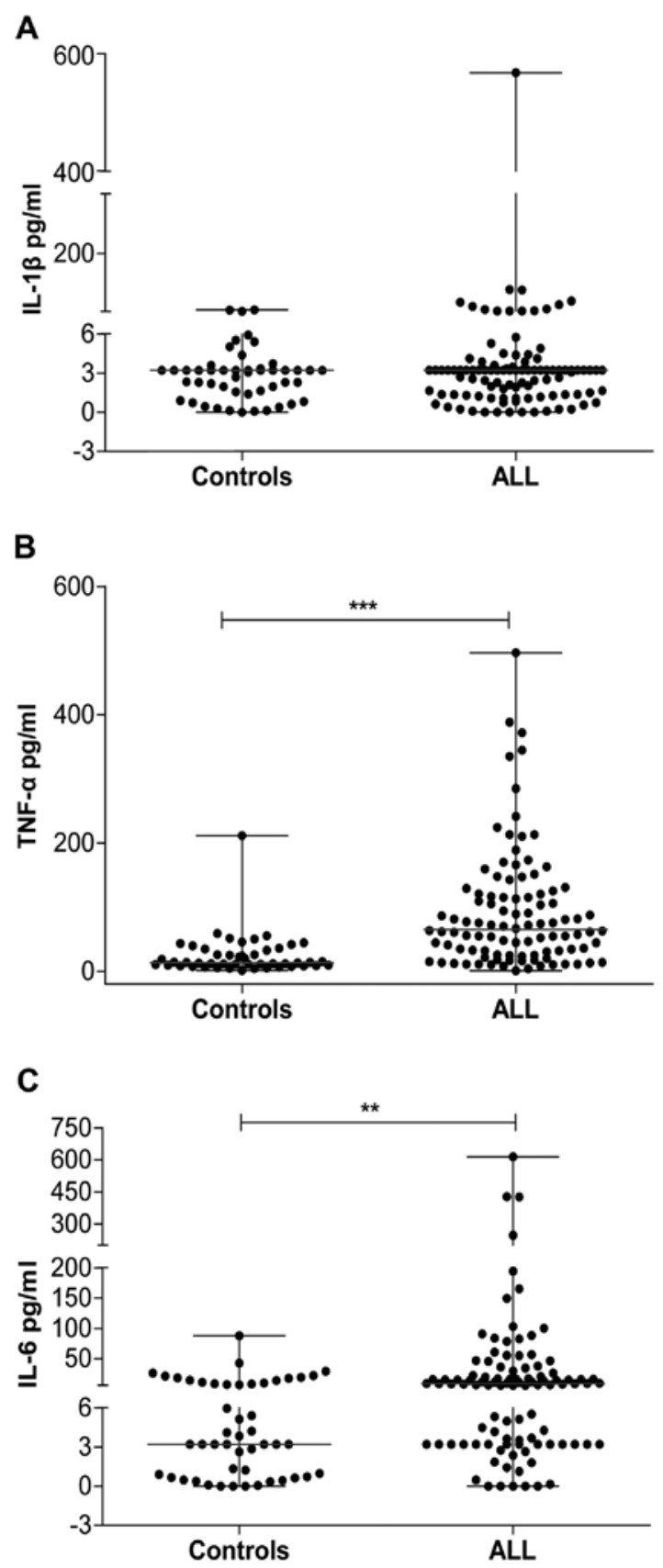

Figure 2. The levels of pro-inflammatory cytokines are increased in patients with acute lymphoblastic leukemia (ALL). The serum levels of (A) interleukin (IL)-1 $\beta$, (B) tumor necrosis factor (TNF)- $\alpha$, and (C) IL-6 in patients with ALL were measured by xMAP. The values are plotted as the median with range. Comparisons between groups were performed using the Mann-Whitney $\mathrm{U}$ test. ${ }^{* * *} \mathrm{P}<0.0001$, and ${ }^{* *} \mathrm{P}<0.0006$ are considered to indicate a statistically significant result.

patients. We found that IL-8 levels were significantly higher in the ALL group (median, $78.75 \mathrm{pg} / \mathrm{ml}$; range, $4.80-24,937 \mathrm{pg} / \mathrm{ml}$ ) than they were in the control group (median, $13.03 \mathrm{pg} / \mathrm{ml}$; range, 2.99-522 pg/ml) (Fig. 3A). The concentration of MCP-1 was also higher in the ALL group (median, $1,090 \mathrm{pg} / \mathrm{ml}$; range, $4.28-4,382 \mathrm{pg} / \mathrm{ml}$ ) compared with the control group (median, $381 \mathrm{pg} / \mathrm{ml}$; range, 2.99-2,001 pg/ml) (Fig. 3B).

T-cell-polarizing cytokines in patients with ALL at diagnosis. We also analyzed the levels of T-cell-polarizing cytokines in
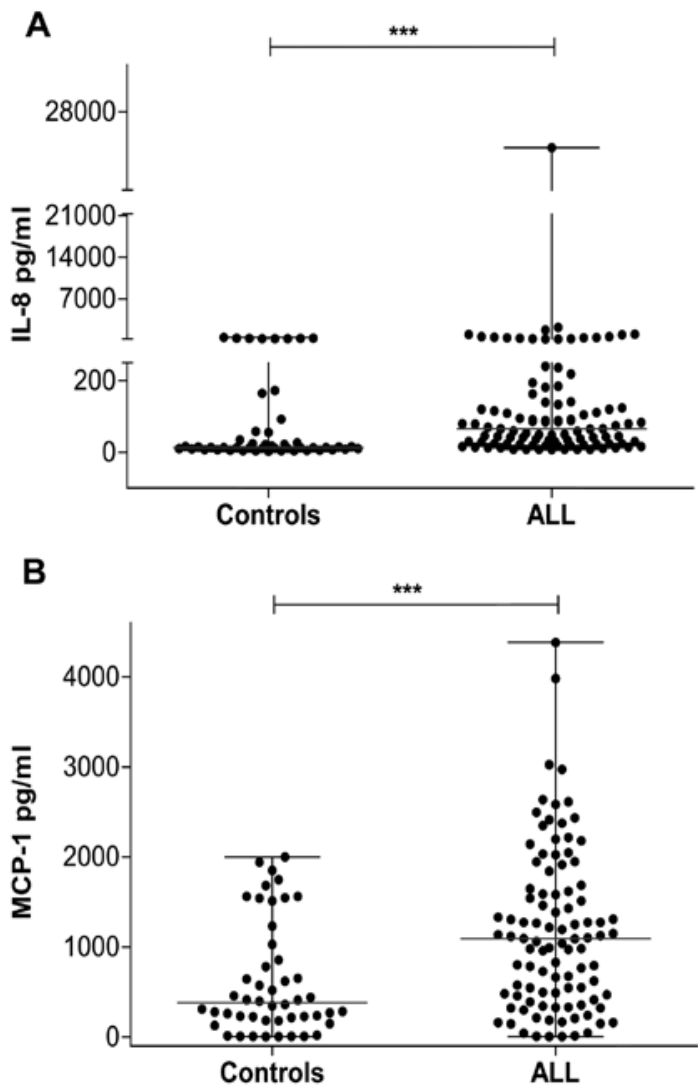

Figure 3. The levels of chemokines are increased in patients with acute lymphoblastic leukemia (ALL). The serum levels of (A) interleukin (IL)-8 and (B) monocyte chemoattractant protein-1 (MCP-1) in the control group and in patients with ALL were measured by xMAP. The values are plotted as the median with interquartile range. Comparisons between groups were performed using the Mann-Whitney U test. MCP-1, monocyte chemoattractant protein- $1{ }^{* * *} \mathrm{P} \leq 0.0001$ is considered to indicate a statistically significant result.

patients with ALL without clinically apparent infection. We analyzed Th1 cytokines such as IFN- $\gamma$, IL-12 and IL-2 (Fig. 4). The circulating levels of IFN- $\gamma$ and IL-12 were significantly higher in patients with ALL than they were in the control group (IFN- $\gamma$ in ALL: median, $6.50 \mathrm{pg} / \mathrm{ml}$; range, $0.0-456.60 \mathrm{pg} / \mathrm{ml}$; IFN- $\gamma$ in controls: median, $3.34 \mathrm{pg} / \mathrm{ml}$; range, $0.38-45.90 \mathrm{pg} / \mathrm{ml}$; IL-12 in ALL: median, $3.20 \mathrm{pg} / \mathrm{ml}$; range, $0.0-175.0 \mathrm{pg} / \mathrm{ml}$; IL-12 in controls: median, $2.63 \mathrm{pg} / \mathrm{ml}$; range, $0.0-70.56 \mathrm{pg} / \mathrm{ml}$ ) (Fig. 4A and B). The levels of IL-2 in patients with ALL (median, $3.20 \mathrm{pg} / \mathrm{ml}$; range, $0.0-83.11 \mathrm{pg} / \mathrm{ml}$ ) and in controls (median, $3.05 \mathrm{pg} / \mathrm{ml}$; range, $0.0-13.61 \mathrm{pg} / \mathrm{ml}$ ) were not significantly different (Fig. 4C).

The levels of Th2 cytokines such as IL-4 and IL-13 were also measured to obtain an idea of the Th1/Th2 cytokine balance in patients with leukemia. The level of IL-4 in patients with ALL was not significantly different from that in the control group. We found that the control and ALL groups had similar circulating levels of this cytokine (Fig. 5A). Conversely, the level of IL-13 was lower in patients with ALL compared with the control group (median, $3.20 \mathrm{vs.} 3.20 \mathrm{pg} / \mathrm{ml}$; range of IL-13 in patients with ALL, $0.0-547.10 \mathrm{pg} / \mathrm{ml}$, but only three patient had a level $>100 \mathrm{pg} / \mathrm{ml}$; range of IL-13 in the control group, $1.93-110.90 \mathrm{pg} / \mathrm{ml}$ ) (Fig. 5B). The Th2 response in these patients was decreased, thereby favoring the Th1 response. 
A

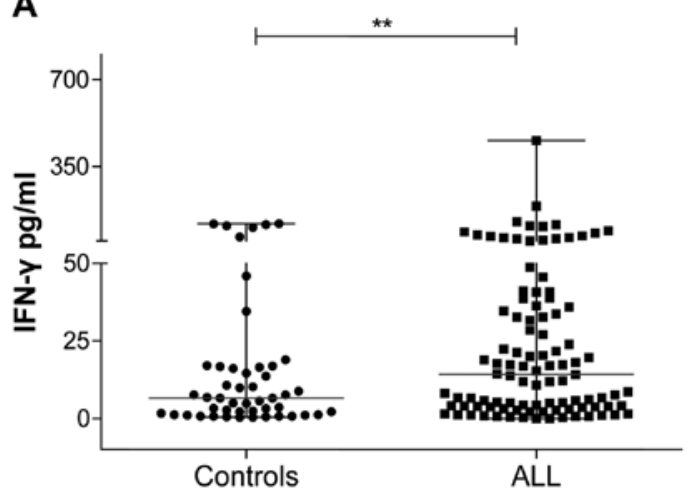

B

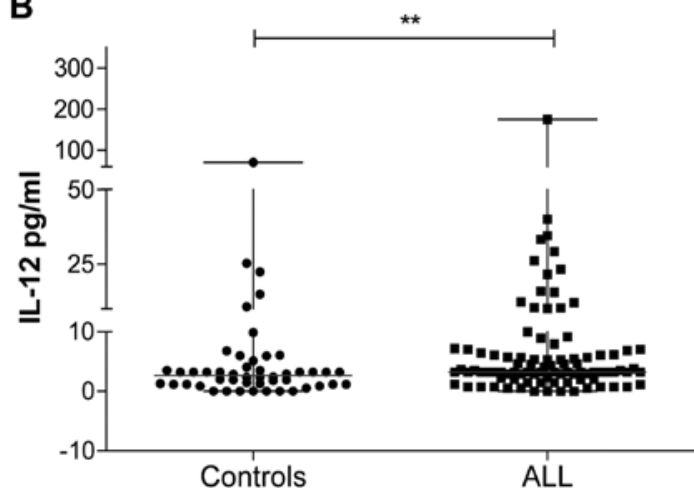

C

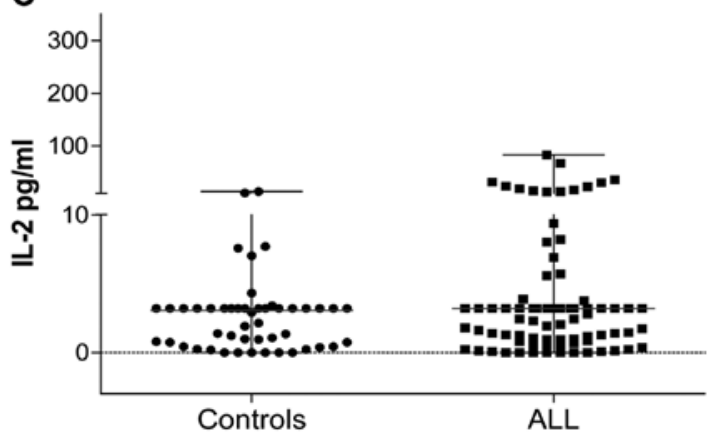

Figure 4. Patients with acute lymphoblastic leukemia (ALL) had an increased Th1 cytokines. The serum levels of (A) interferon- $\gamma($ IFN- $\gamma)$, (B) interleukin (IL)-12, and (C) IL-2 in the control group and in patients with ALL were measured by xMAP. The values are plotted as the median with interquartile range. Comparisons between groups were performed using the Mann-Whitney $\mathrm{U}$ test. ${ }^{* *} \mathrm{P}=0.0234$ and $^{* *} \mathrm{P}=0.0092$ are considered to indicate a statistically significant result.

Together, these results suggest an inclination toward a Th1 profile in ALL, driven by increased Th1 and decreased Th2 cytokines in patients with ALL.

Higher concentration of circulating immunoregulatory cytokines in ALL at diagnosis. The circulating levels of IL-10 were higher in patients with ALL than they were in the control group, with a median of $91.81 \mathrm{vs.} 5.15 \mathrm{pg} / \mathrm{ml}$ (range, $2.47-3,209 \mathrm{pg} / \mathrm{ml}$ for ALL vs. $0.0-73.63 \mathrm{pg} / \mathrm{ml}$ for the control group) (Fig. 6A). The IL-17 level was higher in ALL than it was in the control group, with a median of $3.20 \mathrm{pg} / \mathrm{ml}$ (range, $0.0-139.20 \mathrm{pg} / \mathrm{ml}$ ) in ALL, while in the control group the median was also
A

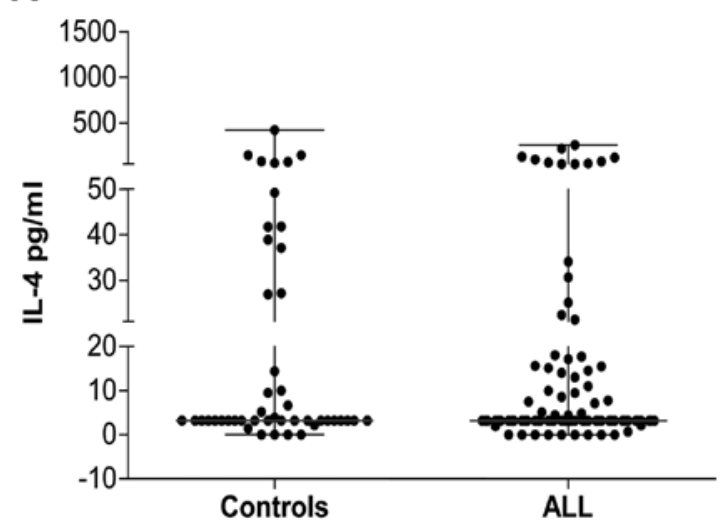

B

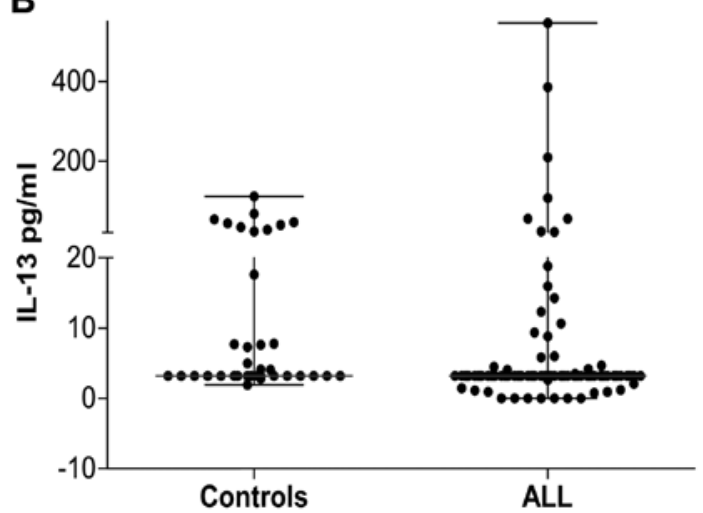

Figure 5. Patients with acute lymphoblastic leukemia (ALL) have a decreased Th2 response. The serum levels of (A) interleukin (IL)- 4 and (B) IL-13 in the control group and in patients with ALL were measured by xMAP. The values are plotted as the median with range. Comparisons between groups were performed using the Mann-Whitney U test. $\mathrm{P}>0.05$ is not significant.

$3.20 \mathrm{pg} / \mathrm{ml}$ but the range was $0.0-75.75 \mathrm{pg} / \mathrm{ml}$ (Fig. 6B). However, TGF- $\beta$ levels were lower in patients with ALL than they were in the control group (median, 1,438 vs. $4,407 \mathrm{pg} / \mathrm{ml}$; range, $0.0-29,507$ vs. $0.0-33,777 \mathrm{pg} / \mathrm{ml}$ ) (Fig. 6C).

The balance of inflammatory, $\mathrm{T}$ cell-polarizing and immunoregulatory cytokines produced in patients with ALL without apparent infection was highly altered; a schematic representation of this alteration is shown in Fig. 7.

\section{Discussion}

Cytokines are regulators of host responses to infection, inflammation and trauma. Some cytokines promote inflammation (pro-inflammatory cytokines), whereas others serve to reduce inflammation and promote the healing of tissue (anti-inflammatory cytokines). Thus, to maintain tissue homeostasis and integrity, the levels of different cytokines are finely tuned and controlled. The deregulation of cytokines plays an important role in different pathologies, including cancer (10-12).

In this study, we showed that, at the systemic level, there was an important pro-inflammatory condition at diagnosis in children with ALL and no apparent infection, i.e., children for whom evidence of infection could not be obtained. We report for the first time the higher concentrations of TNF- $\alpha$ and IL- 6 in patients with ALL with no infection, as elevated levels 

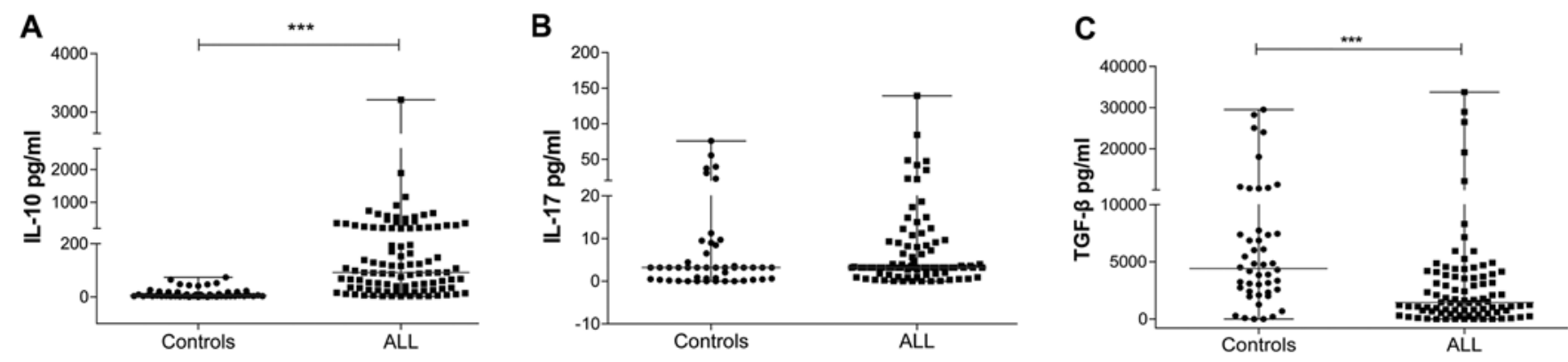

Figure 6. Deregulation of regulatory cytokines in patients with acute lymphoblastic leukemia (ALL). The serum levels of (A) interleukin (IL)-10, (B) transforming growth factor $\beta$ (TGF- $\beta$ ), and (C) IL-17 in the control group and in patients with ALL were measured by xMAP or ELISA. The values are plotted as the median with range. Comparisons between groups were performed using the Mann-Whitney $\mathrm{U}$ test. ${ }^{* * *} \mathrm{P} \leq 0.0001$ is considered to indicate a statistically significant result.

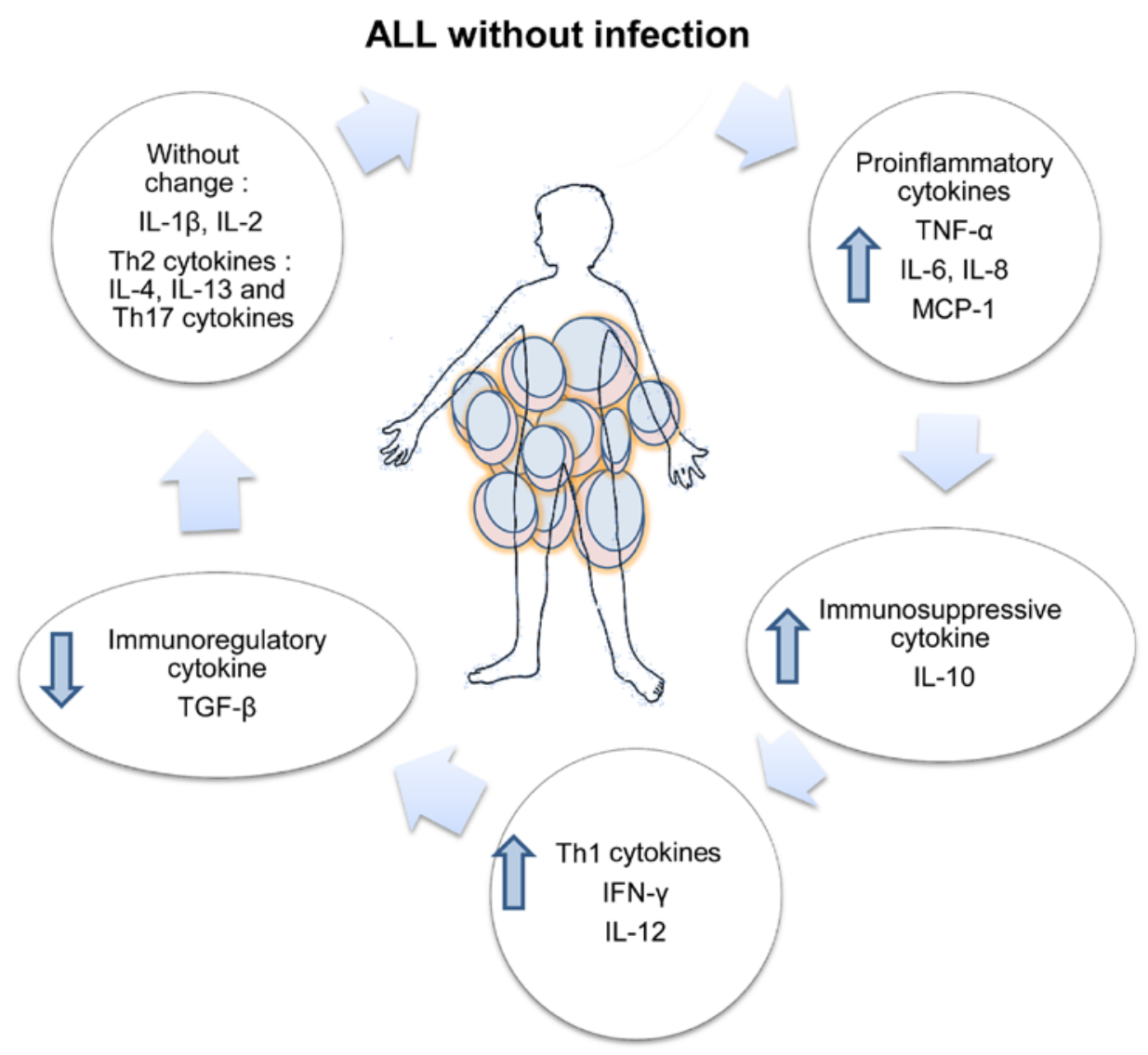

Figure 7. Disrupted cytokine balance in patients with ALL without apparent infection. Schematic representation of the strong inflammatory response, T-cellpolarizing, and altered regulatory cytokines produced in patients with ALL and without apparent infection.

of these cytokines have only been reported in the presence of infectious processes $(13,14)$, but not in sterile conditions. The higher concentrations of TNF- $\alpha$ and IL- 6 found in this research in patients with ALL may be associated with the febrile state presented by some of the children, possibly as a consequence of the activation of the immune cells by DAMPs, which have the ability to generate an immune response in the absence of infectious agents (15). Different cellular signaling pathways operate in response to varying levels of pro-inflammatory cytokines, which can lead to genotoxic damage, cell apoptosis, or cell growth. The increased concentration of proinflammatory cytokines in the serum of patients with leukemia may favor a neoplastic process. Moreover, IL-1 $\beta$, TNF- $\alpha$ and IL-6 are pro-inflammatory cytokines that can induce fever and can regulate each other's levels, depending on their concentration (16).

Furthermore, we showed that this pro-inflammatory state had characteristics of a Th1-polarized response. We found that the concentrations of circulating TNF- $\alpha$, IL-6, IL-8, MCP-1, IL-12, IFN- $\gamma$ and IL-10, were significantly increased in children with ALL. In contrast, the concentrations of TGF- $\beta$ were decreased in ALL and those of IL-1 $\beta$, IL-2, IL-4, IL-13 and IL-17 showed no changes compared with the controls. This finding is significant since it may reflect a sterile inflammation 
in ALL, as all children included in this study did not show apparent infection at diagnosis and had not received any antineoplastic treatment at the time of collection of the blood samples. Recently, the levels of circulating cytokines were studied in adult patients with ALL, and IL-8 and MCP-1 were found to be elevated at diagnosis, thus reflecting disease activity (17).

The results of our study suggest that the increases in IL-6 and IL- 8 in the absence of apparent infection are induced by the activation of other molecules or mechanisms that are independent of infectious microorganisms. IL-6 is important in the maintenance of cancer stem cells in the neoplastic microenvironment of leukemic cells (18) and has been shown to stimulate the growth of AML (acute myeloid leukemia) cells through signaling pathways (19).

Moreover, IL-6 has been reported as a sensitive predictor of bacterial infection in neutropenic as well as non-neutropenic febrile children with ALL (20); in addition, a study of the role of IL-6 and IL-8 in a small group of patients with hematological malignancies showed that they could be useful in excluding the possibility of high-risk infection (21). IL-8 in the serum of patients with ALL in association with Gram-negative infection was found to be increased by 10 -fold compared with the control group (22).

In the present study, we found that high levels of the monocyte chemoattractant protein-1 (MCP-1/CCL2), which is a member of the CC chemokine family, was significantly altered in these patients and may contribute to a sterile inflammatory environment. MCP-1 has previously been shown to play a major role in the migration of monocytes toward human leukemic cells; however, it was unable to increase the cytotoxic effects of monocytes on human leukemic cells (23). A higher level of MCP-1 in the cerebrospinal fluid of children with ALL is associated with central nervous system involvement during therapy (24).

There are reports of a high concentration of various inflammatory cytokines in ALL associated with the presence of infection or in response to chemotherapy (25-28). However, there are no reports of an initial inflammatory process in newly diagnosed patients with ALL without apparent infection.

The regulation of the immune response is important in the process of carcinogenesis, as a deregulated pro-inflammatory state may favor cancer, and inflammation also affects immune surveillance. Cytokines such as IL-10, IL-17 and TGF- $\beta$ have an important function in immune regulation. The biological role of IL-10 in cancer is quite complex; however, the presence of IL-10 in advanced metastases and the positive correlation between serum IL-10 levels and the progression of other diseases suggest a critical role for IL-10 in the cancer microenvironment (29).

IL-17 is a cytokine that is produced by a subset of T helper cells, called 'Th17 cells', which are generated in response to signals from TGF- $\beta$, IL-6 and IL-23 $(30,31)$. IL-17 activates many of the same signaling events as do inflammatory cytokines such as TNF- $\alpha$ and IL- $1 \beta$, and is considered to be an important bridging molecule between the innate and adaptive immune systems (32). A study of the role of this cytokine in leukemia showed that it is increased in the blood and bone marrow in AML patients with poor prognosis compared with healthy donors (33). However, in this study, we did not find significant difference between patients with ALL and the control group. The role of IL-12 in immunosurveillance has been reported in cancer (34); in ALL, the study of this cytokine has been focused on immunotherapy $(35,36)$. Our results indicate that IL-12 and IFN- $\gamma$ were elevated in patients with ALL compared with the control group; thus, there was a Th1-biased immune response in patients with this neoplasia.

Elevated systemic concentrations of these Th1 cytokines may promote an inflammatory microenvironment in the early stages of neoplasia. Alterations in the Th1/Th2 ratio in cancer patients is a common feature of a malignant process and may be the result of a malfunction of Th1 cells, activation of Th2 lymphocytes, or both. We found no change in concentrations of IL-4 and IL-13 (Th2 cytokines) in patients with ALL vs. the controls, which confirmed a predominantly Th1-type response in the patients.

However, in patients with neutropenic fever, therapy is and should remain restricted to antibiotics, even though it is very likely that at least some of these patients do not have an infectious process that causes fever, and that the inflammatorystate-related cancer is the cause of the fever, which opens the possibility of seeking a non-infectious marker that induces cytokines associated with fever and with a strong pro-inflammatory response in children with ALL. Further investigation is needed to establish whether these alterations can be used as a prognostic indicator in ALL.

The findings of this study have important implications for understanding the inflammatory response in patients with ALL and no clinically apparent infection, and the bridge between the innate and adaptive immune responses through T-cell polarization. Higher levels of cytokines may play a crucial role in the pathogenesis of ALL and may be important therapeutic targets and prognostic predictors in episodes of fever of unknown origin and in strong inflammatory responses without apparent infection.

\section{Acknowledgements}

This study was supported by Hospital Infantil de México Federico Gómez, grant HIM/2011/22 and by Terry Fox Fundation, grant HIM/2010/076. Erandi Pérez-Figueroa is a doctoral student from Programa de Doctorado en Ciencias Biológicas, Universidad Nacional Autónoma de México (UNAM) and received a fellowship from CONACYT.

\section{References}

1. Gatta G, Botta L, Rossi S, Aareleid T, Bielska-Lasota M, Clavel J, Dimitrova N, Jakab Z, Kaatsch P, Lacour B, et al; EUROCARE Working Group: Childhood cancer survival in Europe 1999-2007: Results of EUROCARE-5 - a population-based study. Lancet Oncol 15: 35-47, 2014.

2. Landskron G, De la Fuente M, Thuwajit P, Thuwajit C and Hermoso MA: Chronic inflammation and cytokines in the tumor microenvironment. J Immunol Res 2014: 149185, 2014.

3. Chen GY and Nuñez G: Sterile inflammation: Sensing and reacting to damage. Nat Rev Immunol 10: 826-837, 2010.

4. Yang Q, Shi Y, Yang Y, Lou G and Chen Z: The sterile inflammation in the exacerbation of HBV-associated liver injury. Mediators Inflamm 2015: 508681, 2015.

5. Demaria S, Pikarsky E, Karin M, Coussens LM, Chen YC, El-Omar EM, Trinchieri G, Dubinett SM, Mao JT, Szabo E, et al: Cancer and inflammation: Promise for biologic therapy. $\mathrm{J}$ Immunother 33: 335-351, 2010. 
6. Agyeman P, Kontny U, Nadal D, Leibundgut K, Niggli F Simon A, Kronenberg A, Frei R, Escobar H, Kühne T, et al: A prospective multicenter study of microbiologically defined infections in pediatric cancer patients with fever and neutropenia: Swiss Pediatric Oncology Group 2003 fever and neutropenia study. Pediatr Infect Dis J 33: e219-e225, 2014.

7. Khurana M, Lee B and Feusner JH: Fever at diagnosis of pediatric acute lymphoblastic leukemia: Are antibiotics really necessary? J Pediatr Hematol Oncol 37: 498-501, 2015.

8. Santolaya ME, Alvarez AM, Becker A, Cofré J, Enríquez N, O'Ryan M, Payá E, Pilorget J, Salgado C, Tordecilla J, et al: Prospective, multicenter evaluation of risk factors associated with invasive bacterial infection in children with cancer, neutropenia, and fever. J Clin Oncol 19: 3415-3421, 2001.

9. Santolaya ME, Farfán MJ, De La Maza V, Cociña M, Santelices F, Alvarez AM, Avilés CL, Becker A, O'Ryan M, Román P, et al: Diagnosis of bacteremia in febrile neutropenic episodes in children with cancer: Microbiologic and molecular approach Pediatr Infect Dis J 30: 957-961, 2011

10. Barrera L, Montes-Servín E, Barrera A, Ramírez-Tirado LA, Salinas-Parra F, Bañales-Méndez JL, Sandoval-Ríos M and Arrieta Ó: Cytokine profile determined by data-mining analysis set into clusters of non-small-cell lung cancer patients according to prognosis. Ann Oncol 26: 428-435, 2015.

11. Mojtahedi Z, Khademi B, Erfani N, Taregh Y, Rafati Z Malekzadeh $M$ and Ghaderi A: Serum levels of interleukin-7 and interleukin-8 in head and neck squamous cell carcinoma. Indian J Cancer 51: 227-230, 2014

12. Sato T, Terai M, Tamura Y, Alexeev V, Mastrangelo MJ and Selvan SR: Interleukin 10 in the tumor microenvironment: A target for anticancer immunotherapy. Immunol Res 51: 170-182, 2011.

13. Buyukberber N, Buyukberber S, Sevinc A and Camci C: Cytokine concentrations are not predictive of bacteremia in febrile neutropenic patients. Med Oncol 26: 55-61, 2009.

14. Fleischhack G, Cipic D, Juettner J, Hasan C and Bode U: Procalcitonin-a sensitive inflammation marker of febrile episodes in neutropenic children with cancer. Intensive Care Med 26 (Suppl 2): S202-S211, 2000.

15. Castellheim A, Brekke OL, Espevik T, Harboe $M$ and Mollnes TE: Innate immune responses to danger signals in systemic inflammatory response syndrome and sepsis. Scand J Immunol 69: 479-491, 2009.

16. Dinarello CA: Interleukin-1, interleukin-1 receptors and interleukin-1 receptor antagonist. Int Rev Immunol 16: 457-499, 1998

17. Horacek JM, Kupsa T, Vasatova M, Jebavy L and Zak P. Evaluation of serum levels of multiple cytokines and adhesion molecules in patients with newly diagnosed acute lymphoblastic leukemia using biochip array technology. Exp Oncol 35: 229-230, 2013.

18. Zhao C, Chen A, Jamieson CH, Fereshteh M, Abrahamsson A, Blum J, Kwon HY, Kim J, Chute JP, Rizzieri D, et al: Hedgehog signalling is essential for maintenance of cancer stem cells in myeloid leukaemia. Nature 458: 776-779, 2009.

19. Su YC, Li SC, Wu YC, Wang LM, Chao KS and Liao HF: Resveratrol downregulates interleukin-6-stimulated sonic hedgehog signaling in human acute myeloid leukemia. Evid Based Complement Alternat Med 2013: 547430, 2013.

20. Abrahamsson J, Påhlman M and Mellander L: Interleukin 6, but not tumour necrosis factor-alpha, is a good predictor of severe infection in febrile neutropenic and non-neutropenic children with malignancy. Acta Paediatr 86: 1059-1064, 1997.
21. Diepold M, Noellke P, Duffner U, Kontny U and Berner R: Performance of interleukin- 6 and interleukin- 8 serum levels in pediatric oncology patients with neutropenia and fever for the assessment of low-risk. BMC Infect Dis 8: 28, 2008.

22. Wu W, Jia Y, Du S, Tang H, Sun Y and Sun L: Changes of sulfur dioxide, nuclear factor- $\mathrm{\kappa B}$, and interleukin-8 levels in pediatric acute lymphoblastic leukemia with bacterial inflammation. Chin Med J (Engl) 127: 4110-4113, 2014

23. Civini S, Jin P, Ren J, Sabatino M, Castiello L, Jin J, Wang H, Zhao Y, Marincola F and Stroncek D: Leukemia cells induce changes in human bone marrow stromal cells. J Transl Med 11: 298,2013

24. Eisenkraft A, Keidan I, Bielorai B, Keller N, Toren A and Paret G: MCP-1 in the cerebrospinal fluid of children with acute lymphoblastic leukemia. Leuk Res 30: 1259-1261, 2006.

25. Bertolizio G, Stucchi R, Sahillioglu E, Somaini M, Dander E, Biondi A, Jankovic M, D'Amico G and Ingelmo PM: The effects of propofol and ketamine on the cytokine levels of children with acute lymphoblastic leukemia. J Pediatr Hematol Oncol 35: e296-e300, 2013.

26. Du S, Jia Y, Tang H, Sun Y, Wu W, Sun L, Du J, Geng B, Tang C and Jin H: Immune regulation of hydrogen sulfide in children with acute lymphoblastic leukemia. Chin Med J (Engl) 127: 3695-3699, 2014

27. Hatzistilianou M, Rekliti A, Athanassiadou F and Catriu D: Procalcitonin as an early marker of bacterial infection in neutropenic febrile children with acute lymphoblastic leukemia. Inflamm Res 59: 339-347, 2010.

28. Matti BF, Saleem MA and Sabir SF: Assessment of interleukin $1 \beta$ serum level in different responder groups and stages of chronic myeloid leukemia patients on imatinb mesylate therapy. Indian J Hematol Blood Transfus 30: 247-252, 2014.

29. Wang S, Sun M, Gu C, Wang X, Chen D, Zhao E, Jiao X and Zheng J: Expression of CD163, interleukin-10, and interferon-gamma in oral squamous cell carcinoma: Mutual relationships and prognostic implications. Eur J Oral Sci 122: 202-209, 2014.

30. Weaver CT, Hatton RD, Mangan PR and Harrington LE: IL-17 family cytokines and the expanding diversity of effector $\mathrm{T}$ cell lineages. Annu Rev Immunol 25: 821-852, 2007.

31. Weaver CT: Th17: The ascent of a new effector T-cell subset. Preface. Eur J Immunol 39: 634-636, 2009.

32. Kolls JK and Lindén A: Interleukin-17 family members and inflammation. Immunity 21: 467-476, 2004.

33. Han Y, Ye A, Bi L, Wu J, Yu K and Zhang S: Th17 cells and interleukin-17 increase with poor prognosis in patients with acute myeloid leukemia. Cancer Sci 105: 933-942, 2014.

34. Zitvogel L and Kroemer G: $\mathrm{CD} 103^{+}$dendritic cells producing interleukin-12 in anticancer immunosurveillance. Cancer Cell 26: 591-593, 2014.

35. Lehmann D, Spanholtz J, Osl M, Tordoir M, Lipnik K, Bilban M, Schlechta B, Dolstra H and Hofer E: Ex vivo generated natural killer cells acquire typical natural killer receptors and display a cytotoxic gene expression profile similar to peripheral blood natural killer cells. Stem Cells Dev 21: 2926-2938, 2012.

36. Pegram HJ, Purdon TJ, van Leeuwen DG, Curran KJ, Giralt SA, Barker JN and Brentjens RJ: IL-12-secreting CD19-targeted cord blood-derived $\mathrm{T}$ cells for the immunotherapy of B-cell acute lymphoblastic leukemia. Leukemia 29: 415-422, 2015. 